\title{
Globe
}

Revue internationale d'études québécoises

Gilles Marcotte : Le lecteur de poèmes. Précédé de Autobiographie d'un non-poète. Montréal, Boréal, coll. "Papiers collés ", 2000

\section{Mathieu Bélisle}

Volume 6, numéro 1, 2003

URI : https://id.erudit.org/iderudit/1000698ar

DOI : https://doi.org/10.7202/1000698ar

Aller au sommaire du numéro

Éditeur(s)

Globe, Revue internationale d'études québécoises

ISSN

1481-5869 (imprimé)

1923-8231 (numérique)

Découvrir la revue

Citer ce compte rendu

Bélisle, M. (2003). Compte rendu de [Gilles Marcotte : Le lecteur de poèmes. Précédé de Autobiographie d’un non-poète. Montréal, Boréal, coll. « Papiers collés ", 2000]. Globe, 6(1), 171-173. https://doi.org/10.7202/1000698ar d'utilisation que vous pouvez consulter en ligne.

https://apropos.erudit.org/fr/usagers/politique-dutilisation/ 


\section{Recensions}

\section{Gilles Marcotte}

Le lecteur de poèmes

Précédé de Autobiographie d'un non-poète.

Montréal, Boréal, coll. "Papiers collés ", 2000.

Après une double carrière de journaliste et d'universitaire qui a donné à la littérature québécoise quelques-unes de ses études les plus marquantes, Gilles Marcotte, bien loin de s'éloigner de la scène littéraire, s'adonne plus que jamais à l'écriture, du roman à l'essai en passant par le recueil de notes. Du nombre se trouve Le lecteur de poèmes: il s'agit d'un recueil qui reprend quelques études publiées récemment dans diverses revues littéraires québécoises, que l'auteur a légèrement remaniées. Le tout est augmenté de quelques inédits remarquables, notamment des lectures de poèmes de René Char, de Pierre Jean Jouve, de Robert Melançon et de Wallace Stevens, ainsi que d'une Autobiographie d'un non-poète, texte d'ouverture qui donne à l'œuvre l'unité et le ton.

Cette " autobiographie " est une remontée aux sources d'une pratique critique s'étendant sur un demi-siècle, dans laquelle on rencontre les mêmes précautions, minutie et humilité caractéristiques de l'écriture de Gilles Marcotte. L'objet du texte est d'abord le parcours d'un "nonpoète ", syntagme qui souligne à l'envi l'état de négativité, voire de déficit, que l'auteur accorde à ce rôle et qui, dans la foulée, tend à marquer une distance d'avec le travail du critique, distance dont le titre du recueil témoigne déjà, et que ce passage révèle encore: "J'ai longtemps pratiqué la critique; il me semble que je deviens, chaque jour un peu plus exclusivement, un lecteur * (p. 33). Toute la place est ainsi ménagée à la lecture, c'est-à-dire à ce qu'il conviendrait banalement d'appeler la réception, et que Marcotte pratique comme un art à part entière. Pourtant, loin de lui l'idée de réclamer la part de l'artiste, lui qui n'a jamais osé commettre qu'un seul poème, à propos duquel il écrit

Michel Lacroix [éd.], • Recensions ", Globe. Revue internationale d'études québécoises, vol. 6, n० 1, 2003. 


\section{REVUE INTERNATIONALE D'ÉTUDES QUÉBÉCOISES}

d'ailleurs : "C'est bien la honte [...] qui m'a saisi, une honte durable, un sentiment d'insuffisance qui non seulement écarte de moi toute tentative de récidive, mais colore l'ensemble des relations que j'entretiens avec la poésie " (p. 7). L'état de minorité quasiment franciscaine dans lequel l'auteur se place mérite d'être souligné, tant il résonne avec force dans ce recueil.

Le parcours autobiographique du lecteur Gilles Marcotte permet de rencontrer des initiateurs, dont le groupe de l'Hexagone et l'œuvre de Bossuet ( " ce grand flot de langage "), d'observer les premiers travaux de journalisme à Sherbrooke (où il ignorera malheureusement Alfred Desrochers) et au quotidien Le Devoir, où il fourbit ses armes, et de trouver un état d'esprit collectif autour de la littérature et des querelles d'écoles. Le parcours dressé permet également de partager un émerveillement sans cesse renouvelé face à l'œuvre d'un Saint-Denys Garneau, dont la poésie "parle", interpelle directement. Marcotte exprime certains regrets, comme de n'avoir pas su accueillir avec toute l'attention méritée les premières œuvres de Miron (après vingt-cinq ans de critique, il affirme : " jamais je n'avais vraiment lu, ce qui s'appelle lu, un de ses poèmes", p. 31). Parmi ses convictions de lecteur, l'auteur affirme ne jamais isoler la poésie de son contexte, des " appels du quotidien ", des "bruits de la rue ". De plus, il avoue ne pas connaître ce qu'est la " délectation esthétique " des partisans de l'art pour l'art : " je n'ai jamais pu savoir exactement ce que cette expression voulait dire ". Toutefois, il nuance son propos en montrant que l'erreur se trouve tout aussi bien dans un attachement dogmatique aux images psychosociales que dans le culte immodéré des objets d'art. Ce constat le conduit à résister à la normalisation du sens et à la quête d'un "message ", pour investir plutôt l'" opération propre du poème.

Dans les lectures de poèmes (dix études), ce qui frappe d'emblée, c'est la très grande tolérance que l'auteur manifeste à l'égard de la complexité et de l'ambiguité du sens poétique. Jamais il ne conclut définitivement, ni n'arrête la signification de ce qui a la propriété de se mouvoir. Ainsi, l'auteur fait l'éloge du vertige et des paradoxes qui couvent dans l'œuvre de Grandbois, il admire le "langage de contradiction " de René Char, "voué non pas à la reconstruction paradoxale de l'unité [...], mais au maintien, voire à l'exacerbation des contraires, des incompatibles . (p. 96). Le plaisir d'être médusé mène également Marcotte à relever l'incomparable richesse de la poésie apparemment 
- claire, facile à entendre • de Robert Melançon. L'affection pour la complexité n'est pas étrangère à une certaine forme de spiritualité que l'auteur laisse transparaître dans ses lectures. De fait, il parvient à saisir et à convoquer l'ineffable dans la poésie de Rina Lasnier (" [elle] a écrit quelques-uns des plus beaux poèmes de notre littérature *) et dans celle de Robert Marteau, à propos duquel il écrit merveilleusement : "J'entre dans le poème comme dans un "temple", non pour y déchiffrer un système, mais pour y entendre une voix * (p. 119).

L'auteur décoche aussi quelques pointes polémiques, vaguement nostalgiques. À propos de la situation de la poésie dans le champ culturel actuel, il constate qu'elle n'est plus, comme autrefois, un événement, non plus que le moyen de dire des choses essentielles. Bien qu'il ne désespère pas de son pouvoir de parler à chacun, il estime néanmoins qu'elle n'est pour l'instant que l'objet d'étude de spécialistes. À qui penserait que la chanson a pris le relais de la poésie au Québec, il rétorque qu'elle n'est qu'un " art mineur, estimable en lui-même, qui n'a rien à voir avec ce qu['il] appelle la poésie " (p. 32). Enfin, contrairement à ceux qui déploreraient l'absence de battage médiatique autour de l'objet de leur affection, l'auteur se réjouit plutôt " que la poésie n'ait aucune place à la télévision, cette ennemie de l'attention * (p. 33).

Refusant toute "compétence " spécialisée pour ne se prévaloir que de celle, humble mais exigeante, de lecteur (" [...] je ne me sens autorisé par aucune sorte de compétence, si ce n'est celle de la lecture, des habitudes, de l'expérience *), Gilles Marcotte écrit dans une prose élégante, où les phrases se succèdent tranquillement, où le rythme, la composition et la recherche du sens exact n'entravent jamais la compréhension, semblable au "temple " dont il parle à propos de Manteau, tant chaque mot semble traité avec égard. Chaque essai est fait d'une écriture patiente, tant dans ses détours révélateurs que dans ses fins éclairantes, et il s'en dégage une autorité paisible qui n'est pas loin de donner au lecteur de ce Lecteur de poèmes un authentique repos.

Mathieu Bélisle

Université de Montréal 